Synthese manuscript No.

(will be inserted by the editor)

\title{
Does perceptual psychology rule out disjunctivism in the theory of perception?
}

\author{
Charles Goldhaber
}

December 6, 2019

This is a post-peer-review, pre-copyedit version of an article published in Synthese. The final authenticated version is available online at: http://dx.doi.org/10.1007/s11229-019-02508-y

\begin{abstract}
Disjunctivist views in the theory of perception hold that genuine perceptions differ in some relevant kind from misperceptions, such as illusions and hallucinations. In recent papers, Tyler Burge has argued that such views conflict with the basic tenets of perceptual psychology. According to him, perceptual psychology is committed to the view that genuine perceptions and misperceptions produced by the same proximal stimuli must be or involve perceptual states of the same kind. This, he argues, conflicts with disjunctivism. In this paper, I defend epistemological disjunctivism from Burge's inconsistency charge. To this end, I survey the perceptual psychological literature, and reveal that the perceptual kinds they tend to employ differ from and imply nothing about the kinds at issue to the epistemological disjunctivist. I then argue that Burge's concerns with epistemological disjunctivism are best interpreted as motivated not by his commitment to empirical science, but instead by his views in epistemology and human rationality.
\end{abstract}

In "Disjunctivism and Perceptual Psychology" and "Disjunctivism Again," Tyler Burge wages a many-faced attack on a view about the nature of perceptual states which he calls 'disjunctivism.' Disjunctivism about perceptual states is the view that successful and unsuccessful perceptual states are different in some relevant kind. ${ }^{1}$ Burge's allegations against this view span from

University of Pittsburgh, Philosophy Department, 1017 Cathedral of Learning, 4200 Fifth Ave, Pittsburgh, PA, 15260

1 Why does 'disjunctivism' signify this? J.M. Hinton is often credited with being the first to demarcate a disjunctivist view about perceptual states. He expressed the view as a view about the attribution of sensory appearances (or 'perceptions,' when not used as a success word) to subjects, saying that these attributions should be understood as having the status of a disjunctive statement: Either the subject is perceiving things as they are or the subject is experiencing an illusion, hallucination, or misperception. Hinton explains that the "or" 
charges that it is unmotivated (Burge, 2005, 29-30, 40, 43-45; Burge, 2011, $55-56$ ), to worries that it obscures the nature of perceptual fallibility (Burge, $2005,30-31$ ), to a sustained critique of the particular features of its major contemporary proponents' individual views (Burge, 2005, 42-67). But the "main defect" of disjunctivism about perceptual states, Burge thinks, is "its incompatibility with science" - in particular, with the field of perceptual psychology (Burge, 2011, 55). This charge of incompatibility dominates the full body-text of the first essay (Burge, 2005, 1-40) and remains at the core of the second.

In this paper, I assess Burge's main charge against disjunctivism about perceptual states (hereafter, 'disjunctivism'). I argue that Burge is wrongdisjunctivism and perceptual psychology are not at odds. They are not at odds, I explain, because disjunctivism makes claims about kinds of perceptual states about which perceptual psychology is quiet and holds no clear commitments. Disjunctivist views take some features of perceptual states to be essential to those states - for example, their intentional content or the epistemic warrant they provide. Research programs in perceptual psychology typically do not take those particular features to be essential to perceptual states, and so individuate perceptual states at a different level of grain than disjunctivist views do. I argue that this difference in individuation, far from implying any inconsistency, instead demonstrates that the commitments of perceptual psychology have no implications for the truth or falsity of disjunctivism.

There are, of course, many differing disjunctivisms, each developed for its own explanatory purpose. Burge specifies his intended target by giving his own, allegedly sweeping definition. He writes: "Disjunctivism is, roughly, the view that there is never any specific perceptual-state kind in common between perceptions of one object" and illusions that are "contextually indiscriminable to the perceiver from the successful perception" (Burge, 2005, 2). ${ }^{2}$ Of course,

here is meant to emphasize that the two disjuncts attribute mental states that are different in kind (see Hinton, 1967; Hinton, 1969; cf. Soteriou, 2014, §1).

My formulation of disjunctivism about perceptual states is meant as a sweeping, if somewhat elliptical, definition. It gives a genus encompassing many more determinate species of disjunctivisms about perceptual states. To give a complete account, more would need to be said about what 'successful' here amounts to, or what the 'relevant kind' is.

For example, a particular disjunctivist view may take a perceptual state's being successful to be or involve that perceptual state's being veridical. Or it may take that success to be or involve the perceptual state's providing some sort of epistemic warrant, or its having some sort of intentional content. The relevant difference in kind can be cashed out in terms of a difference in the perceptual states' intentional contents (e.g., Campbell, 2002; Tye, 2007), phenomenal characters (e.g., Fish, 2008; Fish, 2009), or rational or epistemological status (e.g., McDowell, 1982; McDowell, 1995; Snowdon, 2005; Pritchard, 2011; Pritchard, 2012). For more on the varieties of disjunctivism, see Soteriou (2014), §2 and French (2014).

2 Burge's definition of disjunctivism is in fact narrower. It also denies that there is any specific perceptual-state kind in common between perceptions of one object and perceptions involving any other object which is contextually indiscriminable to the perceiver. I omit this part of Burge's definition, since it seems to me clear that not all forms of disjunctivism are committed to the thought that all successful perceptual states involve singular reference. A disjunctivism may allow, for example, that an existential perception whose content may be expressed with the sentence "There is a bowling ball" remains successful when the original bowling ball is switched to another, contextually indiscriminable bowling ball. See McDowell (2013), §§4-5; cf. McDowell (2011b), §§2, 10. 
any two given perceptual states share all sorts of kinds, for example, perceptual and mental. So Burge clarifies the thesis to avoid its being trivially false: What disjunctivism denies is that there is a "fundamental, explanatorily relevant" perceptual-state kind that is both shared between and "specific to" successful perceptions and relevant perceptual illusions (Burge, 2005, 25ff). This negative claim entails the positive characterization of disjunctivism given above - that successful and unsuccessful perceptual states differ in some relevant kind. But the negative claim is stronger since it denies more kinds.

I am not sure that anyone holds the thesis as Burge spells it out, which seems to me an unattractive straw man for reasons I will explain below. So in this paper I will assess whether Burge's main charge applies to a certain brand of disjunctivism that I do find attractive. This is an 'epistemological' disjunctivism motivated by the need to explain the fallibility of our perception. When spelling out this view in my discussion below, I will appeal to features of John McDowell's disjunctivism, which is a species of this brand. Doing so has the benefit of making relevant two of McDowell's papers replying to Burge on this issue, both entitled "Tyler Burge on Disjunctivism." Ultimately, though, I develop my own novel replies, and do not just assess the success of McDowell's.

This paper is not meant as a complete defense of disjunctivism. I do not attempt to argue for the merits of any particular disjunctivism-McDowell's or otherwise - over any non-disjunctive account of perceptual states-Burge's or otherwise. I mean only to counter the claim that the sciences rule out disjunctivism as a viable thesis about perceptual states. Most of this more modest defense will be a sustained explanation of why Burge's argument for this claim is off point. But beyond that, I attempt to show that the claim is false, in addition to being insufficiently supported by Burge.

This paper has four sections. In $\S 1$, I survey Burge's argument for the incompatibility of disjunctivism with perceptual psychology, using Burge's definition of disjunctivism. In $\S 2$, I argue that a particular brand of epistemological disjunctivism is immune to Burge's argument. To do this, I supplement McDowell's claims to this effect with a survey of the perceptual psychological literature. The survey suggests that the literature holds no commitments which conflict with this brand of epistemological disjunctivism. $\S 3$ exposits and assesses a related back-and-forth between Burge and McDowell about the nature of perceptual fallibility. Here, I show that Burge's criticism about fallibility fails to support his main charge for two reasons - first, because it mischaracterizes the disjunctivist's position, and second because it is based on epistemological theses which are largely irrelevant to the scientific research on perception. I close in $\S 4$ by explaining that the claim that the sciences rule out any plausible disjunctivism about perceptual states is tenuous given the diversity of approaches and extent of disagreement within the scientific research on perception. 


\section{Burge's inconsistency charge}

Burge's main argument against disjunctivism rejects the thesis as inconsistent with the commitments of perceptual psychology.

Perceptual psychology is an empirical science that studies the relationships between objects in a perceiver's distal environment, responses of the perceiver to registered proximal stimulations, and perceptions had by the perceiver as an effect of these responses. ${ }^{3}$ Its findings include the description and formalizing of the regular mental or brain processes which transform stimulations registered by sense organs into conscious perceptions.

As Burge notes, perceptual psychology is a "serious science" with "wellestablished results and successful application of mathematical methods" (Burge, 2005, 9). Thus, any philosophical thesis which conflicts with the findings or foundational assumptions of perceptual psychology may appear poorly informed or arrogantly anti-scientific, and false either way.

\subsection{Burge's inconsistent triad}

According to Burge, disjunctivism is demonstrably false, because it conflicts with a commitment of perceptual psychology which he terms "the proximality principle." This principle states that, typically, registered proximal stimulation and a perceiver's psychological dispositions sufficiently determine in a lawlike way what kind of perceptual state the perceiver experiences: "Holding constant the antecedent psychological set of the perceiver, a given type of proximal stimulation (over the whole body)... will produce a given type of perceptual state, assuming that there is no malfunctioning in the system and no interference with the system" (Burge, 2005, 22). This is a causal thesis. But it may be helpful to note that it plausibly implies the following supervenience thesis: Typically, no differences in the kind of perceptual state one experiences can occur apart from differences in the kind of stimulations one undergoes or differences in the kind of psychological make up one has. ${ }^{4}$

That disjunctivism apparently clashes with this principle can be demonstrated with an example. Imagine you are walking through a desert. It is hot and wind is kicking sand into the air. Both airborne sand and the radiating heat, which bends the light rays traveling through it, make it difficult to perceive the surrounding environment. Nonetheless, you make out an oasis in the

\footnotetext{
3 'Distal environment' refers to familiar features of the environment outside or surrounding the perceiver. This contrasts with 'proximal stimulation,' which refers to features and states of the perceivers sense organs, like the activation of photoreceptors on the eye's retina.

4 The "typically" here is meant to bar cases of serious malfunctioning and interference, which might undermine the otherwise law-like connection between stimulations and perceptual states. Burge does not specify what sort of malfunctions or interruptions he has in mind, but some simple candidates may include strokes and tampering with perceptual pathways using electrodes.

For the sake of brevity and clarity, I will follow Burge in holding constant the perceiver's psychological make up throughout the remainder of the paper.
} 
distance. You successfully perceive the oasis. Let us call this the 'oasis case.' Now imagine being in more-or-less the same circumstances, except that there is no oasis. In this case, what appears to be an oasis is a mere mirage, an illusion or misperception. Let us call this the 'mirage case.'

Let us stipulate that the light arrays registered by your retina's photoreceptors are identical in both the oasis and mirage cases. (The ambiguity caused by airborne sand and radiating heat perhaps makes this easy enough to imagine.) According to the proximality principle, the identical proximal stimulation in the two cases necessitates your being in or experiencing identical perceptual states (barring any significant malfunctioning or interference in your perceptual pathways). The states are certainly indistinguishable, since in both cases your perceptual state is of an oasis. But according to Burge's definition of disjunctivism, there is no perceptual-kind shared between your perceptual states in the two cases, despite their being indistinguishable from one another.

Note that disjunctivism as Burge spells it out does not a priori contradict the proximality principle. For if, as a matter of fact or empirical law, we never (or always) misperceived, then no one set of proximal stimulations could give rise to successful perceptions in some contexts and unsuccessful perceptions in others. Disjunctivism could then be non-trivially true without a given proximal stimulation's ever resulting in perceptual states that differ in a kind that disjunctivism denies can be shared between successful and unsuccessful perceptions. But as things are, Burge notes, "perception of entities in the distal environment is fallible. The Proximality Principle, together with this empirical fact, entails that the same type of perceptual state can be veridical and non-veridical" or, more generally, successful or unsuccessful (Burge, 2005, 27). And this directly conflicts with the disjunctivism as Burge spells it out, which denies that a type or kind ${ }^{5}$ of perceptual state can be shared between relevant successful and unsuccessful perceptual states.

Burge's charge that disjunctivism is inconsistent with perceptual psychology can thus be boiled down to the following (somewhat idealized) inconsistent triad:

(1) Fallibility: Type-identical proximal stimulations can lead to both successful and unsuccessful perceptual states, depending on context.

(2) Proximality: Type-identical proximal stimulations produce typeidentical perceptual states.

(3) Disjunctivism: There are no perceptual-state types shared between successful and unsuccessful perceptual states.

Fallibility and Proximality combine into:

(4) Anti-disjunctivism: Successful and unsuccessful perceptual states are type-identical when the proximal stimulations causing them are type-identical.

And Anti-disjunctivism clearly conflicts with Disjunctivism.

\footnotetext{
5 I, like Burge, use 'type' and 'kind' interchangeably.
} 


\subsection{Underdetermination and fallibility}

Now that we have before us the inconsistent triad, it will help to show that Fallibility and Proximality are really empirical facts or commitments of perceptual psychology. Otherwise their conflicting with Disjunctivism may be insufficient grounds for rejecting Disjunctivism as the faulty premise.

Fallibility is a fairly common-sense idea. We are all familiar with the thought that in some circumstances we might be caused to misperceive. From afar you might take, for example, a painting of a landscape to be a window onto the countryside. The light-arrays registered by your eyes may perhaps even be type-identical to the ones that they would have registered had the painting actually been a window onto the countryside. In both the actual misperceiving and the counterfactual perceiving, the proximal stimulation is identical. So the same proximal stimulation can lead to both successful and unsuccessful perceptions.

The idea here is common sense, but it is explained and reinforced by the science of perception. The reason type-identical proximal stimulation can lead to both successful and unsuccessful perceptions is that information taken in through those proximal stimulations may underdetermine how things are in the distal environment. By describing the mechanisms involved in perception, the science of perception provides the resources for explaining this underdetermination.

This is easy to see with human vision. Perceptual science explains that the proximal stimulations which give rise to visual perceptions are, primarily, firings of cones and rods on the retina. These firings respond to and encode a twodimensional projection of light focused by the cornea. These two-dimensional images are ambiguous to many different possible three-dimensional layouts of objects in the environment. ${ }^{6}$ Of course, vision allows us to perceive a threedimensional world. The mechanisms involved in human vision have (imperfect) means for getting around the underdetermination and constructing a threedimensional environment: Human beings typically have two eyes. This allows for some degree of depth perception through automatic, internal triangulation between the two two-dimensional projections registered by the two eyes. ${ }^{7} \mathrm{Hu}-$ man depth perception sometimes also incorporates cues from the stereoscopic polarization and chromatic diffraction of the registered light arrays. ${ }^{8}$

Ultimately, however, some ambiguity remains. For example, in both our eyes, there is a blind spot. No photoreceptors cover the optic disc, the spot where the optic nerve connects with the back of the eye. Typically, one eye's blind spot is "filled in" in perception by a combination of information from the other eye and information from the patterns immediately surrounding the blind spot. But blind spots are often filled in incorrectly. This can easily be made apparent by closing one eye and focusing just a bit to the side of, for

\footnotetext{
${ }^{6}$ See Palmer (1999), 23-24 on vision's "inverse" problem for a nice illustration of this phenomenon.

7 See Cutting and Vishton (1995) and Ramachandran and Rogers-Ramachandran (2009).

8 See De Silva et al (2011), 498 and Faubert (1994), 1665 respectively.
} 
example, a small pockmark on a wall in the opposite direction of the eye which remains open. ${ }^{9}$

Additionally, our stereoscopic depth perception has little nuance beyond ten meters' distance; when stationary, we are unable to tell apart a chair at fifteen meters from a larger chair at twenty meters in absence of landmarks for comparison. ${ }^{10}$ In such cases, the discrepancies between the light-arrays projected upon the retina of each eye will be too insignificant to be registered. So the proximal stimulation will be the same in both cases. This implies Fallibil$i t y$, since the very same proximal stimulation can lead us to perceive correctly or incorrectly.

\subsection{Constancy mechanisms and the proximality principle}

According to Burge, the proximality principle is "basic in nearly all scientific study of perception." He sees the principle as "necessary to any explanation that would show how perceptions are formed on the basis of proximal stimulations" (Burge, 2005, 29). Why might this be?

For Burge, perceptual psychology's paradigm objects of study are the mechanisms which transform information encoded by proximal stimulations into full-blown conscious perceptions. In the case of vision, these are the mechanisms which bridge the registering of light arrays on retinal detectors with concious visual perceptions.

As noted in the previous subsection, the information encoded by proximal stimulations often underdetermines how things are in the distal environment. But perceptions themselves are fully determinate. Burge notes that perceptual psychology studies the mechanisms that transform the ambiguous data into determinate perceptions. It is a basic assumption of this science, then, "to take[, for example,] the visual system to operate under certain principles in the formation of perception" (Burge, 2005, 12). These principles describe law-like regularities in the functioning of the perceptual mechanisms which bridge proximal stimulations and perceptions. Burge appropriately calls these principles "biases" or "biasing principles," since they bias us to interpret ambiguous data one way as opposed to another. These biasing principles may lead us astray, but tend to lead to successful perceptions when perceivers are in their normal environments. ${ }^{11}$

\footnotetext{
9 See Palmer (1999), 34 and Schwartz (2009), 12-16.

10 Distances extending in front of an unmoving human observer, orthogonal to her line of sight are systematically and exponentially foreshortened in vision: egocentric distances of 10,100 and $1000 \mathrm{~m}$ are seen as 9,79 , and $710 \mathrm{~m}$ resulting in a 10, 21 and $29 \%$ error (Cutting and Vishton, 1995, 73)..

11 Burge's talk of biasing principles is meant to cohere with a number of terms from the scientific literature and science textbooks. What is central to these principles is that they augment perceptual information. In augmenting the perceptual information, the principles explains how perception can be made more determinate or rich than ambiguous proximal information.

Compare, for example, Burge's biasing principles with Palmer's "heuristic processes": "the visual system transcends the available optical information by implicitly making a num-
} 
Burge's taking perceptual psychology to hold the basic assumption that perceptual systems operate under principles of perception formation leads him to view the proximality principle as a core commitment of that science. For if all perceptual states are reached through law-like transformations of proximal stimulations according to biases, then what proximal stimulations initiate a perceptual state will determine (again: according to biases) which perceptual state that is. If we take the biasing principles to be included within one's psychological dispositions, then we effectively have the proximality principle, which implies that there can be no changes in perceptual states without changes in proximal stimulation or psychological dispositions. ${ }^{12}$

Still, the basic assumptions of a putative science are not themselves reason to take those assumptions as well-grounded. If perceptual psychology's basic assumption of principles of perception formation were to lead to no firm empirical findings, it would not serve as a good reason to take the proximality principle as true. And this would undermine Burge's argument against the disjunctivist.

For this reason, Burge gives examples of "uncontroversial, well-known empirical facts" and generalizations established by perceptual psychology (Burge, 2005, 9). In particular, he notes that perceptual psychology has displayed its merit through having found, described, and mathematized regularities in perceived lightness constancy and in perceived slant of textured planar surfaces (Burge, 2005, 14-18). ${ }^{13}$

ber of highly plausible assumptions about the nature of the environment and the conditions under which it is viewed. When these assumptions are coupled with sensory data in the incoming image, they result in a heuristic interpretation process in which the visual system makes inferences about the most likely environmental condition that could have produced the image. The process is heuristic because it makes use of probabilistic rules of thumb that are usually, but not always, true. If these underlying assumptions are false, they will lead to erroneous conclusions in the form of visual illusions" (Palmer, 1999, 58; cf. 23-24). Burge's biasing principles are meant to express generalizations about how Palmer's heuristic processes work. They encode, so to speak, the 'rules of inference' that govern the heuristic processes. Compare also "constraints" in Poggio et al (1985), 314 and even von Helmholtz's "unbewußter Schluß" or "unconscious inference" (von Helmholtz, 1867).

12 I think there are significant reasons to doubt Burge's logic here, which I discuss below in n. 24. But my argument against Burge will not rely on doubting this. So I will grant for the sake of argument that perceptual psychology is in fact committed to the proximality principle.

13 Lightness constancy is the perception of achromatic surfaces as having the same lightness through differing illumination conditions. For example, a page of a book appears roughly equally white, and the text on it equally black, inside and outside. This is so despite the fact that when outside the black text may reflect as much as ten times the light that the white page did when inside. This creates "the scaling problem of lightness perception": Are there any general rules governing the mapping of luminance ratios onto a perceived blackand-white scale? Empirical research using lightness illusions have helped to reveal that small light regions with sharply defined borders that are surrounded by dark regions function as optimal "heuristic anchors," setting white and black values (Gilchrist, 1988; Palmer, 1999, 125-133; Adelson, 2000; Daw, 2012).

Many surfaces we encounter, including especially ground surfaces, have statistically regular textures. Light reflected from such surfaces produce light arrays called texture gradients. Proximal stimulations registering texture gradients with regular patterns that vary in size and density give the impression of slanted planes. Quantifiable models of the heuristic pro- 
1.4 Why give up disjunctivism?

Burge's inconsistent triad implies a contradiction. This warrants the denial of one of its three premises. But why should that lead us to drop Disjunctivism over the other two?

Burge's basic thought seems to be that it is the least motivated of the triad's propositions. Fallibility makes a seemingly undeniable, common sense claim, which is confirmed and explained by perceptual science. Proximality, Burge takes himself to have shown, is a principle "basic" to perceptual psychology, which is a "serious science." Disjunctivism, on the other hand, Burge calls "unmotivated." He criticizes it for being nothing more than an "overreaction to veil-of-perception views of the British empiricists" (Burge, 2005, 30). Burge thinks that once we recognize that this supposed empiricist threat is now an idle phantom which "nearly all serious philosophical positions reject," we lose any philosophical reasons for holding Disjunctivism.

Burge's claim that disjunctivism is poorly motivated plays an important role in his argument. For if there were strong philosophical motivations for holding that view, their existence could perhaps constitute a reason to worry that it is the science which stands on shaky ground.

I am sympathetic to the claim that there are real philosophical motivations which count in favor of disjunctivism. But I am equally sympathetic to Burge's attitude that philosophy must be consistent with what science reveals. So I think any doubting of a science on philosophical grounds should be treated as a last resort. We should take care, then, to see first whether we can explain away the apparent inconsistency as merely apparent. I do this in the next section.

\section{No inconsistency}

Burge's inconsistent triad is surely inconsistent. But does this show that disjunctivism is ruled out by the commitments of perceptual science? It does only if Burge's definition of disjunctivism actually characterizes all of the plausible or well motivated forms of disjunctivism.

In this section, I show that it does not. I believe that many - even mostforms of disjunctivism are not properly characterized by Burge's definition. But it will be sufficient to show that just one prevalent and well motivated form is not properly so characterized in order to block Burge's argument. I will thus present a form called 'epistemological disjunctivism,' and show that it is not properly so characterized. I will then show that there is little independent reason to think that this view conflicts with the science.

cesses resulting from these cues have been developed through research using two-dimensional texture illusions (Gibson, 1950; Knill, 1998a; Knill, 1998b; Bruce et al, 2003, 303). 


\subsection{Epistemological disjunctivism and what it explains}

Epistemological disjunctivism typically takes it to be fundamental to the nature of successful perceptual states, the ones that bring us in contact with our environment, that these perceptual states carry a special or strong epistemic warrant: The warrant thus provided is sufficient for the perceiver to form knowledgeable beliefs about her environment. Hallucinations, illusions and other misperceptions on the other hand, do not carry this special epistemic warrant, even when they are subjectively indistinguishable from the successful perceptions. Misperceptions and successful perceptions, then, are different in epistemic kind. ${ }^{14}$

Epistemological disjunctivism can seem trivial. For how could misperceptions provide us with a warrant strong enough to form knowledgeable beliefs ${ }^{15}$ about our environment? Misperceptions by nature do not put us in contact with our environment. So anyone who understands these concepts must accept that they cannot carry such strong epistemic warrants.

But the thesis is not trivial. It is relatively commonplace to think that nothing beyond what is subjectively available to a perceiver can make a difference to her epistemic standing on some matter. It can then seem to follow since hallucinations and successful perceptions can be subjectively indistinguishable, they cannot, on this view, have a different effect on the perceiver's epistemic standing.

Epistemological disjunctivism conflicts with the seeming implication of the commonplace thought, and is often motivated as a means of avoiding the skepticism which seems to follow from the implication. If no perceptual state can provide an epistemic warrant beyond that which a subjectively indistinguishable hallucination provides, it seems that no perceptual state can-by itself - warrant perceptual knowledge. This bleak picture can be avoided by denying, as the epistemological disjunctivist does, that successful perceptions and hallucinations have the same epistemic status.

Proponents of epistemological disjunctivism have, therefore, argued for the view as a means of avoiding this skepticism (e.g., McDowell, 1982). But the bleak picture does not quite imply skepticism. For one can still allow that perceptual states can provide epistemic warrants sufficient for knowledgeable be-

\footnotetext{
14 McDowell clearly holds this view: "My disjunctivism denies that perceptions and corresponding misperceptions are individuated together at the level that is fundamental to epistemology" (McDowell, 2013, 272). See also Duncan Pritchard's epistemological disjunctivism. This, according to him, is "the rejection of the idea that the... rational support one possesses in favour of one's perceptual belief is the same regardless of whether one is having a normal veridical perceptual experience as opposed to being the victim of an introspectively indistinguishable experience which is in fact deceptive or untrustworthy in some way (e.g., a hallucination)" (Pritchard, 2011, 434). "[The] two rational standings are radically different in kind (this is what makes this epistemological proposal disjunctivist)" (Pritchard, 2012, 161).

15 A belief is 'knowledgeable' when it counts as knowledge if adopted on the relevant subjectively available grounds - in this case, a relevant perception. A belief can perhaps be justified without being knowledgeable, as in justified false belief. A belief may perhaps even be justified and true without being knowledgeable, as in Gettier cases.
} 
lief when experienced in conjunction with certain other conditions obtainingfor example, an appropriate causal relation between the perceptual state and the state of affairs thereby revealed. Perceptual states could then still make a crucial contribution to our coming to know our environment. But such "conjunctivist" views of perceptual states face significant difficulties, like spelling out what exact contributions the perceptual state and external conditions respectively make, and how these contributions combine to provide an epistemic warrant sufficient for knowledgeable belief.

The epistemological disjunctivist opts for a simpler picture of the relationship between perceptual states and these strong epistemic warrants. On her view, the epistemic warrant a perceptual state provides is fundamental to the kind of perceptual state it is. Experiencing perceptual states of a certain epistemologically privileged kind is sufficient for forming knowledgeable beliefs about one's environment; no further conditions need obtain. ${ }^{16}$

Epistemological disjunctivism thus explains in a simple way how perception is a fallible capacity for knowledge: ${ }^{17}$ Exercises of this capacity, i.e., perceptual states, are of one of two subjectively indistinguishable kinds. Either the perceptual state is of the epistemologically privileged kind and by itself puts us in a position to form knowledgeable beliefs about our environment, or the perceptual state is not of this kind and merely appears to put us in this position. Perception is a capacity for knowledge because its successful exercises are sufficient for putting us in a position to form knowledgeable belief. No conditions external to those involved in a successful exercise need obtain. ${ }^{18}$ And the capacity is fallible because it can produce both successful and unsuccessful exercises.

\subsection{Does Burge's definition apply?}

Burge sometimes says or implies that disjunctivism denies that there is "any" perceptual state kind in common between successful and unsuccessful percep-

16 Epistemological disjunctivism has been criticized as essentially quietist or uninformative. For one may want to know what features of a perceptual state account for its being of one epistemic kind and not the other. If the epistemological disjunctivist does not say anything about what features of a perceptual state account for its revealing features of the surrounding environment, then it may seem that the view has asserted that perceptual states can give rise to knowledge without explaining how.

I think that this criticism is unfair. Epistemological disjunctivism does not deny that anything can be said about what features of successful perceptual states account for their putting us in touch with features of the environment. It only denies that these features are extrinsic to the successful perceptual state.

17 I borrow this formulation from McDowell. Calling perception a capacity for knowledge expresses the idea that perception is itself responsible for the rationality of knowledgeable perceptual belief. I flesh out this idea in more detail in $\S 3$ below. See also McDowell (2011a), McDowell (2011b), §§3-4. Cf. Sellars (1997), §§29, 31 and 36.

18 On such a conception, representing things correctly, or having a true content, is essential to genuine cases of perception. In this way, the truth condition on perceptual knowledge is not external to the perceptual capacity, but is necessarily satisfied by successful exercises of that capacity. 
tual states (Burge, 2005, 2, 24, 25, 28). It is easy to see that epistemological disjunctivism need not deny as much as Burge characterizes it as denying in these remarks. For epistemological disjunctivism denies only that successful and unsuccessful perceptual states are of the same epistemological kind. It can therefore stay neutral about whether any other perceptual state kinds are shared.

As mentioned already, Burge refines his characterization of disjunctivism. He emphasizes in a later article that the characterizations mentioned above are "rough" and get "sharpened and supplemented" elsewhere in the article (Burge, 2011, 45ff). What disjunctivism denies, according to Burge's sharpened definition, is that any fundamental and explanatorily relevant perceptual kind is both shared by and specific to indistinguishable successful and unsuccessful perceptual states. So the question becomes: Can epistemological disjunctivism allow that any fundamental and explanatorily relevant perceptual kind is had by both a successful perceptual state and an indistinguishable hallucination, and only had by those perceptual states?

To answer this, we need to clarify 'fundamental' and 'explanatorily relevant.' Unfortunately, Burge does not say much about what work he intends the word 'fundamental' to do. Presumably, it is meant at least to rule out uninteresting, extrinsic kinds which perceptual states may bear, such as: experienced by so-and-so or experienced on July 22nd. 'Fundamental' suggests a kind that is intimately related to the nature of a perceptual state qua perceptual state. An example may perhaps be having a certain phenomenal character, since having some determinate phenomenal character may be seen as an essential feature of perceptual states.

Of course, what kinds are intimately related to the nature of a perceptual state depends on what a perceptual state is thought to be. After all, 'perceptual state' is a theoretical notion, so what a perceptual state amounts to is therefore bound up in the theory which employs that notion. Such theories are employed for certain explanatory purposes. So the notion of a perceptual state, and therefore what kinds are 'fundamental' to a perceptual state, depend on the explanatory work for which the notion is employed. It is not clear, then, whether Burge's specifying the state that the disjunctivist denies can be shared as 'fundamental' adds anything to his specifying that state as 'explanatorily relevant.' And Burge's remark that fundamental kinds are "the most fine-grained kinds that ground systematic explanation" corroborates this thought (Burge, 2011, 72n13).

So we can now ask: Must epistemological disjunctivism deny that there is some kind shared only by successful perceptual states and indistinguishable illusions or misperceptions which contribute to the explanation that the theory gives?

I think that the answer is no. For epistemological disjunctivism not only can incorporate such a kind, but it may have a compelling reason to, given its explanatory project. The theory, as I explained in the previous subsection, gives an account of perception as a fallible capacity for knowledge of features of one's environment. It is a condition on the fallibility of this capacity that 
we sometimes are unable to recognize that a perceptual state that we are currently experiencing does not reveal features of the world, but is instead illusory. A very natural way to explain this inability is that both successful perceptual states and indistinguishable illusions and misperceptions do in fact share a relevant kind. We might say that they are both of the following kind: 'making it appear to us as if such-and-such is the case.' This notion of an appearance is important. For if a kind of appearing were not shared between successful and corresponding unsuccessful perceptual states, then presumably we could tell whether our perceptual states were successful or not by appealing to differences in how things appear to us. And then our perception could not be fallible in the sense we normally take it to be. ${ }^{19}$

The kind 'makes it appear as if such-and-such is the case' is specific only to successful perceptions that such-and-such is the case and misperceptions which make it appear as if such-and-such is the case. This follows from the disjunctivist thesis that appearances that such-and-such is the case are either successful perceptions, which provide warrant for knowledgeable belief that such-and-such is the case, or misperceptions, which provide no such warrant. These disjuncts are exhaustive, since - by the law of excluded middle - a perceptual state either does or does not provide a perceptual warrant sufficient for knowledgeable belief that such-and-such is the case.

Epistemological disjunctivism is therefore not properly characterized by even Burge's refined definition.

\subsection{The explanatory projects of perceptual psychology}

Even if Burge's sharpened definition fails to capture epistemological disjunctivism, his charge that it conflicts with perceptual science may nonetheless be

19 Even if successful perceptions and corresponding misperceptions could never make things appear to us in the same way, we could still fail to recognize we are misperceiving out of a kind of negligence or laziness. But typically we think of perception as fallible in a further sense: We think that sometimes we are unable to tell, through no negligence on our part, that we are hallucinating or misperceiving.

Here, I do not mean to claim that appealing to a common perceptual kind is the only way to make sense of the alleged introspective indistinguishability between a case of perception and its corresponding case of hallucination. Some disjunctivists take the indistinguishability to be a purely epistemological fact. According to M.G.F. Martin, for example: "the relevant conception of what it is for one thing to be indiscriminable from another is that of not possibly knowing it to be distinct from the other" (Martin, 2006, 363ff). Someone's inability to know that two things are distinct need not be explained by the two things' sharing a common kind - at least not a kind which is an instance of "the privileged classifications of individuals... that our talk of what is essential to a given individual tracks" (Martin, 2006, 361). I suspect that Martin would deny that the kind "making it appear as if such-and-such is the case' is a "privileged classification" of perceptions, given his "Naive Realist" analysis of "sensory experiences" as, paradigmatically, "relations to mind-independent objects" (Martin, 2006, 354). I am less clear whether he must then deny that this kind can play any role in the explanation of the indistinguishability at issue-perhaps as a placeholder implying the existence of some so far unspecified epistemic facts. Either way, I have argued that at least some disjunctivist theories can and perhaps should appeal to a kind shared between and specific to genuine perceptions and corresponding hallucinations. 
sound. For a contradiction could still be reached if it turns out that this form of disjunctivism denies that the perceptual state kind that the proximality principle implies ${ }^{20}$ is common to successful and unsuccessful perceptual states caused by type-identical proximal stimuli is indeed common to them.

I do not think that epistemological disjunctivism is committed to this denial. The reason is simple. All this form of disjunctivism denies is that successful and unsuccessful perceptual states share an epistemic kind. It need not deny that they share any other perceptual state kinds, or that these can be explanatorily relevant to different explanatory projects. ${ }^{21}$

Is the kind that proximality principle implies is common an epistemic kind? I think not. In order to show this, it helps to return to the perceptual psychology that Burge claims is committed to the proximality principle. Burge writes the following about perceptual psychology:

The methodology of the science is, wherever possible, to match, clarify, sharpen, and make sense of (often by roughly confirming, sometimes by seriously correcting) the introspective conscious reports of human individuals. It attributes such states to non-human individuals on the basis of discriminative behavior. It integrates ordinary, conscious perceivings and misperceivings by individuals into a system including nonperceptual states and processes; and it explains, in systematic, mathematicized ways, how those perceptual states are formed and affect other states.

Burge, 2011, 67

Burge's description makes no clear reference to epistemic kinds. He describes the science as identifying the relevant perceptual states by using conscious reports and other behavioral cues. He does not describe it as further individuating perceptual states with respect to whether they provide human and animal subjects accurate information about the environment.

Note that this description of the science and its methodology contrasts with other of Burge's remarks, such as: "The aim of the psychology of vision is to explain how the perceptual system gets things (approximately) right" (Burge, 2005, 14). This second description seems to me inaccurate. Burge's claim may seem to accord with David Marr's description of the computational approach to vision science, which portrays vision as an information processing procedure whose "underlying task is to derive properties of the world from images of it" (Marr, 1982, 23). But even this does not imply that Marrian computational research projects attempt to explain how perception gets things right. For an explanation of aspects of how a system that is, so to speak, "engineered" for epistemological contact with the environment functions need not extend so far as explaining how it achieves this contact. This is analogous to how an explanation of the electronics in a calculator need not go so far as to explain how the calculator yields correct mathematical results.

\footnotetext{
20 In conjunction with Fallibility.

21 See Byrne and Logue (2008) and Snowdon (2005) for arguments for this point.
} 
It is plausible that the biasing principles which the science describes developed through natural selection, securing the evolutionarily advantageous end of an accurate purview of the environment. But this fact is irrelevant to describing and mathematicizing those principles. The principles generalize relationships between measurable stimuli and discriminative behavior, including measurable testimony. In order for these principles to concern perceptual states, then, there must be a reliable correlation of perceptual state kinds with testimonial and behavioral kinds. That does not require that the perceptual state kinds be individuated as finely as epistemic kinds, for behavioral kinds are definable apart from epistemic standings.

Even when notions of success do make their way into the psychological literature, the notions are not clearly epistemological. Especially in research projects in the Gibsonian vein, perception is seen as a capacity developed over time for the survival benefit of the species. Though an accurate purview of one's environment may be one way of securing this survival advantage, it need not be the only way. A rodent, for example, may enjoy statistically higher survival success if it interprets most registrations of movements in its periphery vision as predators, even when there are none. The view of reality that the perception provides is then thought to be species relative, constructed in virtue of what benefits that species's survival. ${ }^{22}$

But even in research projects in the Marrian vein, where studies of visual illusions are prevalent, notions of success come apart from epistemological notions. Researchers do not always criticize the visual system as functioning improperly when it gives rise to illusory perceptions. Instead, they often see themselves as putting the visual system outside of its regular environments in order to tease out the biasing principles. In strange environments, like the Ames' room, they often describe the visual system as functioning correctly by interpreting things differently than they in fact are. ${ }^{23}$ Knill, for example, identifies "ideal observers" as "optimal estimators" who pick up on textural cues (like texel position, scaling and foreshortening) regardless of whether these cues correctly portray the environment in unusual situations (Knill, 1998a, 1686; Knill, 1998b, 1657). These sorts of studies may perhaps take for granted epistemic notions, when differentiating between illusory and veridical perceptual states. But they should not therefore be interpreted as making claims about how the visual system puts us in touch with reality. Any potentially epistemic notions are instead employed for the purpose of understanding the functioning of biasing principles, in abstraction from how much epistemological success these principles bring us. ${ }^{24}$

\footnotetext{
22 See, for example, Gibson (1986); Goldstein (1999), 258-259; Palmer (1999), 6-7. See also the literature on frog eye "bug detectors" following Barlow (1953).

23 See Palmer (1999), 247-248 for a discussion of the Ames room.

24 Note that these illusion-based studies should shed doubt on Burge's attributing the proximality principle to perceptual psychology as a "basic" assumption. This is, in part, because these studies distinguish between successful and illusory perceptual states as part of their experimental data. The tests are also engineered so that these two perceptual states result from identical registrations of light arrays. This is easy to see with lightness illusions, where patches of the same hue appear of different hues based on surroundings (for a collection
} 
Study of biasing principles and heuristic processes neither yields, nor is intended to yield, epistemological conclusions. A survey of the methods and explanenda of studies in the perceptual psychological literature that Burge cites (which are broadly in the Marrian vein) corroborates this. Their goal is more accurately expressed in terms of the description and mathematization of biasing principles, quite apart from how these principles bring reality in view. ${ }^{25}$ The latter would seem to require a further inquiry about the conditions under which these principles succeed in making us aware of genuine features of the world, and perhaps also how and when those conditions can be known to obtain.

In fact, at one point Burge seems to admit as much. He says: "Notions of warrant do not appear in psychology" (Burge, 2011, 68). This suggests that within psychology, perceptual kinds are not individuated at the level of epistemic kinds. It can therefore seem surprising that Burge criticizes all forms of disjunctivism for being "incompatible with the methodology of the science" (Burge, 2005, 41). It seems he has either overlooked epistemological disjunctivism or failed to understand what it claims. ${ }^{26}$ For how could it conflict with the science if all it denies is something about which the science stays neutral?

\section{An epistemological debate}

The considerations in $\S 2$ show that Burge's argument for disjunctivism's incompatibility with perceptual psychology fails. Nonetheless, it is important to engage with another aspect of Burge's criticism of disjunctivism and the debate with McDowell it generates. I do this not because I think Burge's considerations aid his main charge against disjunctivism, even prima facie. Rather, I think they are worth considering because they reveal that the crux of Burge's attack on disjunctivism is epistemologically rather than scientifically motivated. On the one hand, this looks bad for Burge, for it questions whether his argument against disjunctivism is really made on scientific grounds. But on the other hand, this can be seen as good news for Burge, for it reveals that there is a serious epistemological debate in the vicinity, which presents a new route of attack on at least the epistemological variety of disjunctivism.

of such illusions, see Adelson, 2000, 342-350). The identity of registered light arrays in combination with distinguishing between successful and illusory perceptions caused by these identical registrations conflicts with the proximality principle. It is ironic, then, that Burge (almost exclusively) cites literature exploiting illusion.

25 For example, see the data motivated formulas modeling the transformation of textural cues in Knill (1998b), esp. pp. 1657-1664.

26 McDowell charges Burge with misunderstanding epistemological disjunctivism in both McDowell (2011b) and McDowell (2013). See especially $\S \S 1-3,7$ in the former and $\S \S 1-2,6-$ 8, 27 in the latter. My defense against Burge goes beyond McDowell's in part because of the arguments I give in this subsection $(\S 2.3)$. Here, I argued that perceptual psychology is not committed to the view that genuine perceptions and misperceptions caused by type-identical proximal stimuli must be of the same epistemological kind. 


\subsection{Burge's fallibility criticism}

In "Disjunctivism and Perceptual Psychology," Burge asserts that "what we understand by a capacity's being referentially fallible is that it is realized in state types that could have been mistaken. The same state type could have failed to have a referent... [including] perceptual state types that underlie or are involved in cases of seeings." For Burge, it is a necessary condition on a perceptual state's representing things as they are that it successfully refers to things in the environment. Accordingly, Burge analyzes the fallibility of perception in terms of any perceptual state type's possibly lacking reference. He then goes on to claim that "[d]isjunctivism denies the existence of such state types," and in doing so obscures the nature of our perceptual fallibility (Burge, 2005, 31).

This criticism is idle for two reasons. First, as I have already argued, disjunctivism need not deny the existence of the relevant perceptual state kind: An appearing that such-and-such is the case seems like a fine example of a perceptual state type that does or does not refer, depending on context. It refers to features of the environment when the appearing is in fact a seeing, and it fails to refer when the appearing is mere appearance.

Second, this is an unusual analysis of our perceptual fallibility. 'Fallibility' is a term that normally attaches to persons or capacities, not to exercises of capacities. McDowell goes so far as to criticize Burge's position as incoherent. He dismisses it as "a confusion to think that the idea of fallibility can intelligibly carry over to" perceptual states qua exercises of a perceptual capacity. In locating the fallibility in perceptual states themselves, Burge seems to get rid of the idea of a perceptual state which, by itself, puts us in a position to form knowledgeable belief about our environment.

McDowell illustrates the point with an analogy to the imperfect capacity to make free throws. According to him, on Burge's logic "[o]ne might as well think that there cannot be a capacity - of course not guaranteed success on all occasions - in whose non-defective exercises one actually makes free throws" (McDowell, 2011b, §3). If the imperfection of the free throwing capacity were to be analyzed analogously to Burge's analysis of perceptual fallibility, any given free throw attempt must possibly not be a successful free throw. This holds even of the non-defective exercises, which are in fact successful free throws. And a capacity whose non-defective exercises might not be successful free throws is not a capacity to make free throws.

Burge responds to this second criticism in "Disjunctivism Again," saying that his analysis of perceptual fallibility is "clearly intelligible." Calling a perceptual state fallible, according to him, "attribut[es] a modal property to a particular": "It is metaphysically possible for those exercises to be, or have been, mistaken" (Burge, 2011, 53). Burge reappropriates McDowell's analogy to illustrate. He claims that it is metaphysically possible that any actually successful free throw be unsuccessful in different circumstances, for example, had a gust of wind blown the ball off course. Similarly, it is metaphysically possible that any actually successful perceptual state be unsuccessful in dif- 
ferent circumstances, for example, had things been different than how they appeared (Burge, 2011, 54).

\subsection{Mischaracterization of disjunctivism}

I agree that Burge's analysis is not unintelligible. But I think it does not constitute a point against the epistemological disjunctivist's view.

Burge's analysis is not unintelligible, since Burge is certainly right that it is metaphysically possible that any perceptual state -individuated at the level of the kind he endorses - either refers or fails to refer to features of the environment, depending on circumstances. Metaphysically possible changes in the environment allow for this possibility.

But the epistemological disjunctivist is not obliged to accept this analysis. On her view, perception is taken to be a capacity for knowledge, or in McDowell's words, "a capacity to be in a state in which environmental realities are perceptually present to the subject, so that when the capacity is nondefectively in operation, the subject has experiences that conclusively warrant associated belief" (McDowell, 2013, §16). Accordingly, the epistemic warrant a perceptual state carries is taken to be fundamental to the kind of perceptual state it is. If it is fundamental or essential to a perceptual state that it carries this strong epistemic warrant, then it is not metaphysically possible for that state to not carry this warrant. To claim this is to misidentify the capacity the epistemological disjunctivist wants to explain. Burge's analysis sees perception as a capacity to be in perceptual states, but not by itself a capacity for knowledge.

Again, McDowell's analogy with imperfect capacity to make free throws is helpful. Burge's claim that it is metaphysically possible that even a successful free throw have missed is of course true, if the free throw is conceived of as the launching of a basket ball in abstraction from whether it makes into the basket. This may perhaps be how we tend to think about free throws. But here I agree with McDowell that "this is irrelevant" to understanding the imperfection of the capacity (McDowell, 2013, $\S 16$ ). For the capacity is not merely a capacity to launch balls from the free throw line regardless of where the ball may land; it is a capacity to make free throws. That means that successful exercises of this capacity are free throws that make it into the basket. And it is not metaphysically possible for free throws that make it into the basket to miss the basket.

The point of McDowell's analogy is to show that "if a capacity is liable to have defective exercises, that puts no constraints on what it can be a capacity to do, and thus on how its non-defective exercises are correctly characterized" (McDowell, 2013, §16). The possibility of missing a free throw does not force us to conceive of the capacity to make free throws as merely a capacity to launch balls from the free throw line. Similarly, the possibility of having an unsuccessful perceptual state does not force us to conceive of our perceptual 
capacity as one that cannot itself issue in epistemic warrants sufficient for forming knowledgeable belief.

Burge is right that it is not incoherent to speak about a capacity to be in perceptual states simpliciter, rather than to be in successful ones, sufficient for basing knowledgeable beliefs. But he is wrong to think that a reflection on our fallibility obliges one to speak that way. If one does, one must go far beyond perception to tell the whole story of perceptual epistemology.

\subsection{Burge's epistemological motivations}

In the previous subsection, I showed that Burge and the epistemological disjunctivist hold competing views of perceptual fallibility, each involving different conceptions of what a perceptual capacity is. I also showed that the possibility of failure does not force the adoption of one view over the other. Burge's criticism of disjunctivism on the ground that it obscures the notion of perceptual fallibility, then, falls limp without an independent reason to think one view of fallibility (or else one view of what the perceptual capacity is a capacity for) is forced, or the other false.

Does Burge give any reason to prefer his analysis of fallibility, or his view of what the perceptual capacity is a capacity for? Burge suggests that the epistemological disjunctivist's picture of perception as a capacity for knowledge is flawed because it presents a poor picture of reasoning. It does so because nondefective exercises provide a warrant sufficient for knowledgeable belief. Such an indefeasible warrant, according to Burge, implies that "apparent counterconsiderations have no rational force" and so "is incompatible with how we reason" (Burge, 2011, 61). There are no perceptual warrants, Burge thinks, that cannot be defeated by, for example, expert testimonial evidence otherwise.

This is a core element of Burge's view, which predates his criticism of disjunctivism. For example, in a paper predating "Disjunctivism and Perceptual Psychology" by three years, he says: "It is a fundamental feature of perceptual warrant, hence perceptual entitlement, that it allows that an individual can be fooled while retaining warrant" (Burge, 2003, 536). For Burge, perceptual warrant alone is not a sufficient basis for knowledgeable belief. Knowledgeable belief requires, first, an absence of counter-considerations which could defeat the warrant. And, second, it requires an organism's being in circumstances where its naturally selected biasing principles mesh appropriately with regularities in the environment to produce veridical perceptions. Burge writes:

In normal circumstances, the initiations of the psychological processes by natural law combine with the normal workings of the perceptual system and belief-forming system to yield true perceptual beliefs. This. . . is a matter of being in the normal situation in which psychological laws and the non-psychological natural laws of nature that engendered those law-like patterns of belief formation are aligned.

Burge, 2011, 62; cf. Burge, 2003, 536 
As a result, "All states (type or token) and all perceptual competencies are subject to possible error[, since] any perceiver could be placed in a situation in which any given perceptual state-type could be regularly mistaken" (Burge, 2003, 535).

Burge's take on the nature of our perceptual capacity is thus motivated by two epistemological ideas. One is that the rational contribution of perception to knowledge does not extend beyond what is subjectively available to the agent. The other is that the conditions for knowledge nonetheless extend beyond what is subjectively available. In particular, they involve psychological laws attuned to physical ones through the causal history of an organism or species.

The epistemological disjunctivist embraces the first of these epistemological ideas, but not the second. Instead, she holds that the work that Burge relegates to relevant psychological laws is accomplished by successful exercises of the perceptual capacity. Perception itself, when it functions properly, makes features of our environment subjectively available. ${ }^{27}$ And once those features are available to us, no counter-considerations can remove them from that availability. The warrant provided by successful exercises of the perceptual capacity is indefeasible. ${ }^{28}$

There is a real disagreement here. It concerns whether something outside of the warrant given by a perceptual state is always necessary for perceptual knowledge. I do not think that either Burge or McDowell have decided this matter.

Neither do I think that science has. Burge's view may appear prima facie more in tune with the sciences for explicitly incorporating elements familiar from evolutionary theory. But the epistemological disjunctivist can also incorporate these elements within the conditions of the possibility of a perceptual capacity. More importantly, as I explain in $\S 2.3$, the perceptual psychological literature is silent on epistemological matters. The deep tension, then, is to be decided within the field of epistemology.

27 This seems to be the point of the evocative imagery that McDowell eventually cashes out in terms of perception's providing indefeasible warrant: For example, he says that perceptual experience can be "revelatory of the world;" when it is, some feature of reality "there for the subject; in successful exercises of our perceptual capacity, things being thus and so are "manifest" to the subject as "an element in the subject's inner world" (McDowell, 2011b, 253; 245-246; 244-245, 252). Pritchard perhaps captures the same idea by saying that good cases of perception offer us rational support "which is both factive... and reflectively accessible" (Pritchard, 2012, 13). The idea here seems to be that in such cases the perceiver can, through reflection, see that things are as she perceives them to be.

28 This is not to deny that entertaining counter-considerations would make it irrational to form beliefs based on proper exercises of perception. If a person comes to (falsely) believe that she has ingested LSD, or that a painting is in fact a window onto the countryside, then she may no longer be able to rationally form the belief that there is a landscapepainting before her, even on the basis of her correctly perceiving that there is. This is because her unfortunate, false beliefs are inconsistent with this perceptual belief. In this way, taking on bad counter-considerations can temporarily disable one's ability to gain perceptual knowledge, even when when perceives correctly. But this is not to say that the warrant provided by a correct perception is defeasible, or cannot be a basis for knowledgeable belief as soon as the counter-considerations are jettisoned. Indeed, some disjunctivists may even hold that the warrant can still serve as a sufficient reason to jettison the false beliefs. 


\section{Diversity and tolerance}

Burge's argument that disjunctivism is ruled out on scientific grounds fails. But it is worth considering whether there is still dissonance between perceptual science and disjunctivism in any of its forms. For this to occur, the scientific literature must attribute a common kind across perceptual states that disjunctivism denies can be common. I have already suggested that perceptual science does not attribute a common epistemic kind, thereby not conflicting with epistemological disjunctivism. More generally, I think it is tenuous to think that the science obliges to see as common any of the sorts of kinds the various forms of disjunctivisms deny can be common.

A simple reflection on the current diversity in the perceptual scientific literature suggests this. There is a great deal of discrepancies and disagreements within, for example, vision science. Because of this, it seems hasty to think that the scientific literature forces one conception of the correct individuation of perceptual states. When it seems that it does, this can usually be overturned by widening one's scope to incorporate more live research programs.

I will briefly consider one strand of disagreement within perceptual science to suggest the diversity of research approaches it encompasses. This diversity suggests that the science, in its current state, does not privilege any one picture of the correct individuation of perceptual states.

For example, not all research programs take perception, and perceptual states, to be representational. Burge seems to glide over this fact when he asserts that, like him, "[t]he psychology is also committed to some of the information [made available through perception's] being representational" (Burge, $2005,13)$. Certainly some of the literature interested in representational constancy mechanisms, such as those operative in lightness constancy, do take it for granted that perception, and perceptual states, are representational. But elsewhere, such as in the "ecological" approaches to perception launched by J.J. Gibson, talk of representational content is avoided.

Burge only mentions Gibson once in his discussion of disjunctivism, in a footnote suggesting his irrelevance to the picture of perceptual psychology Burge develops (Burge, 2005, 68n11). Burge is not alone in holding a dismissive attitude toward Gibson and the "ecological psychologist" program his work has inspired. Psychologists of competing programs, especially those influenced by computational approaches, have shown great pessimism about the aversion to representation championed by Gibson and his followers. ${ }^{29}$ Still, ecological psychology is still very much alive. ${ }^{30}$ Computational approaches to research on perception, which take perception to be representational, are perhaps more

29 Ken Nakayama of the Harvard Vision Laboratory, for example, says the following about the aversion: "Whether this reflects a defensible ideological position as articulated by [Gibson's] followers, a pragmatic ordering of research priorities as indicated by Gibson himself, or a fundamental naïveté as suggested by Marr, this almost blatant disinterest in the face of steady and often brilliant progress in the fields of neuroscience and psychophysics strikes me as a major limitation, particularly now" (Nakayama, 1994, 334).

30 An example of a current Gibsonian research topic is affordances, or perceived opportunities for behavioral responses. For examples of recent papers, see Chemero (2011), Ch. 6 
prevalent. But this does not amount to a consensus in the science. Given the current state of perceptual science, the science should not be taken to oblige one to take perceptual states to be representational, or individuated with respect to representational content. ${ }^{31}$

This quick foray into disagreement within perceptual science, of course, falls short of proving that there is nothing which the science agrees about that could conflict with disjunctivism. But it is suggestive of this. Many disjunctivisms in the theory of perception deny that successful and unsuccessful perceptual states share kinds which are plausibly had only by states with representational content - for example, certain intentional content kinds and epistemological kinds. ${ }^{32}$ Given that there is insufficient consensus in science to see it as committed to perceptual states' being representational, it would be surprising if there were sufficient consensus in science to see it as committed to perceptual states' having a particular intentional content or epistemological status. It seems even less likely that science would be committed to successful and indistinguishable unsuccessful perceptual states' sharing a particular kind of intentional content or epistemological status. By the same token, the scientific disagreement about whether perceptual states are representational makes it tenuous to see the science as holding any univocal or stable commitments which could conflict with non-representational disjunctivist views. ${ }^{33}$ Either way, it is hard to see why science would come into conflict with disjunctivism.

It is plausible to think, instead, that perceptual science and disjunctivism treat perceptual states at a different level of grain, proper to their different inquiries. They do not conflict with one another because they pursue different explanatory projects. ${ }^{34}$ Those engaged in either project, then, can view the other with an attitude of tolerance. Any differences in the way they treat what they call 'perceptual states' point not to inconsistencies, but to the diversity of inquiries.

\section{Conclusion}

Burge takes himself to have shown that disjunctivist views fail because they deny that perceptual state kinds which science sees as common to perceptions and indistinguishable misperceptions are in fact common. He thinks that this

and Ch. 7, esp. p. 108. A collection of citations to contemporary ecological psychologist literature on related topics is listed on p. 114.

31 For an argument, contra Burge, that science obliges a non-representational approach, see Ganson et al (2014).

32 See $\mathrm{n} .1$ on the varieties of disjunctivism about perceptual states.

33 See, for example, Martin (2006). He claims that genuine perceptions are nonrepresentational relations to objects, while hallucinations are not.

34 Some have argued that certain research programs in visual science are not only consistent with disjunctivism, but also provide support for the latter. See, for example, Beaton (2016). I omit a discussion of such arguments here, because they do not hold of all live research programs. My main argument in $\S 4$ draws on the diversity of competing programs. 
shows an arrogance - a refusal to be receptive to what "well-grounded, rigorous science" says. With notable bravado, Burge criticizes disjunctivism for attempting a "conceptual inquir[y]... insulated from empirical knowledge." This, he thinks, makes it "irrelevant to the advancing of the knowledge of humankind." Disjunctivists, he thinks, ought to look closer at the aims and findings of empirical science, and rethink their views, or else "philosophical progress will continue to pass [them] by" (Burge, 2011, 70-71).

I think it is Burge who ought to be more receptive to the inquiries of others. For in defining disjunctivism as denying any common (explanatorily relevant) perceptual state kind, he fails to engage with most of the disjunctivist views that anyone currently holds. The disjunctivist's denial can be - and, as far as I can tell, almost always is - much more modest.

Once we realize this, we should begin to doubt Burge's incompatibility charge. Disjunctivism's admittedly conceptual inquiry, though not motivated by scientific findings, need not for that reason be seen as arrogantly ignorant or anti-scientific. I showed in $\S 2$ that disjunctivism and perceptual science need not be seen as conflicting. They pursue different explanatory projects, which, though concerning related subjects, conceive of their subjects differently, and carry them into different terrains. And it seems unlikely that the terrains overlap sufficiently to allow for conflict, as I suggested in $\S \S 2.3$ and 4 .

Ultimately, Burge's complaint against the disjunctivist is more soundly motivated epistemologically than scientifically. As I explain in $\S 3$, there is an interesting and unsettled debate in the vicinity. This is the epistemological debate between disjunctivism and "conjunctivism": A debate about whether the grounds for typical cases of perceptual knowledge must involve more than what perception itself makes available to us - or, in other words, whether perception alone can be thought to be a capacity for knowledge of our environment. Burge's charging the disjunctivist with anti-scientific arrogance can draw our attention away from this properly epistemological debate. In arguing against Burge's charge, then, I hope to win the epistemological debate more airtime. ${ }^{35}$

\section{References}

Adelson EH (2000) Lightness perception and lightness illusion. In: Gazzaniga (2000), pp 339-351

Barlow H (1953) Summation and inhibition in the frog's retina. Journal of Physiology 119(1):69-88

Beaton M (2016) Sensorimotor direct realism: How we enact our world. Constructivist Foundations 11(2):265-276

Bruce V, Green PR, Georgeson MA (2003) Visual Perception: Physiology, Psychology, \& Ecology. 4th ed., Psychology Press, Taylor \& Francis Group, New York, NY

\footnotetext{
35 I would like to thank Mazviita Chirimuuta, Eugene Chislenko, Jim Hutchinson, and two anonymous reviewers at Synthese for their helpful comments.
} 
Burge T (2003) Perceptual entitlement. Philosophy and Phenomenological Research 67:503-48

Burge T (2005) Disjunctivism and perceptual psychology. Philosophical Topics $33(1): 1-78$

Burge T (2011) Disjunctivism again. Philosophical Explorations 14(1):43-80

Byrne A, Logue H (2008) Either/or. In: Haddock and Macpherson (2008)

Campbell J (2002) Berkeley's puzzle. In: Gendler and Hawthorne (2002)

Chemero A (2011) Radical Embodied Cognitive Science. MIT Press, Cambridge, MA

Cutting JE, Vishton PM (1995) Perceiving layout and knowing distances: The integration, relative potency, and contextual use of different information about depth. In: Epstein and Rogers (1995), pp 69-117

Daw N (2012) How Vision Works: The Physiological Mechanisms Behind What We See. Oxford University Press, Oxford

De Silva D, Fernando W, Worrall S, Kodikara Arachchi H, Kondoz A (2011) Sensitivity analysis of the human visual system for depth cues in stereoscopic 3d displays. IEEE Transactions on Multimedia 13(3):498-506

Epstein W, Rogers S (1995) Handbook of Perception and Cognition, vol 5: Perception of Space and Motion. Academic Press, London

Faubert J (1994) Seeing depth in colour: More than just what meets the eye. Vision Research 34(9):1165-1186

Fish WC (2008) Disjunctivism, indistinguishility, and the nature of hallucination. In: Haddock and Macpherson (2008), pp 144-167

Fish WC (2009) Perception, Hallucination, and Illusion. Oxford University Press, Oxford

French C (2014) The formulation of epistemological disjunctivism. Philosophy and Phenomenological Research 89(1)

Ganson T, Bronner B, Kerr A (2014) Burge's defense of perceptual content. Philosophy and Phenomenological Research 88(3):556-573

Gazzaniga M (2000) The New Cognitive Nueroscience. 2nd ed., MIT Press, Cambridge, MA

Gendler T, Hawthorne J (2002) Conceivability and Possibility. Oxford University Press, Oxford

Gendler TS, Hawthorne JP (eds) (2006) Perceptual Experience. Oxford University Press, Oxford

Gibson J (1950) The perception of visual systems. American Journal of Psychology 63:367-384

Gibson J (1986) The Ecological Approach to Visual Perception. Lawrence Erlbaum Associates, Hillsdale, NJ

Gilchrist AL (1988) Lightness contrast and failures of constance: A common explanation. Perception \& Psychophysics 43(5):415-424

Goldstein E (1999) Sensation and Perception. 5th ed., Cengage Learning, Belmont, $\mathrm{CA}$

Haddock A, Macpherson F (2008) Disjunctivism: Perception, Action, Knowledge. Oxford University Press, Oxford, UK 
von Helmholtz H (1867) Handbuch der physiologischen Optik. Leopold Voss, Leipzig

Hinton J (1967) Visual experiences. Mind 76(302):217-227

Hinton J (1969) Experiences: An Inquiry Into Some Ambiguities. Clarendon Press, Oxford

Knill DC (1998a) Discrimination of planar surface slant from texture: Human and ideal observers compared. Vision Research 38:1683-1711

Knill DC (1998b) Surface orientation from texture: Ideal observers, generic observers and the information content of texture cues. Vision Research $38: 1655-1682$

Marr D (1982) Vision: A Computational Approach. MIT Press, Cambridge, MA

Martin M (2006) On being alienated. In: Gendler and Hawthorne (2006), pp $354-410$

McDowell J (1982) Criteria, defeasibility, and knowledge. Proceedings of the British Academy 68:455-479

McDowell J (1995) Knowledge and the internal. Philosophy and Phenomenological Research 55(4):877-93

McDowell J (2011a) Perception as a Capacity for Knowledge. Marquette University Press, Milwaukee, WI

McDowell J (2011b) Tyler Burge on disjunctivism. Philosophical Explorations 13(3):243-255

McDowell J (2013) Tyler Burge on disjunctivism (ii). Philosophical Explorations 16(3):259-279

Nakayama K (1994) James J. Gibson - an appreciation. Psychological Review 101:329-335

Palmer SE (1999) Vision Science: Photons to Phenomenology. MIT Press, Cambridge, MA

Poggio T, Torre V, Koch C (1985) Computational vision and regularization theory. Nature 317:314-319

Pritchard D (2011) Epistemological disjunctivism and the basis problem. Philosophical Issues 21(1):434-455

Pritchard D (2012) Epistemological Disjunctivism. Oxford University Press, Oxford

Ramachandran VS, Rogers-Ramachandran D (2009) Two eyes, two views: Your brain and depth perception. Scientific American Magazine

Schwartz S (2009) Visual Perception: A Clinical Orientation, Fourth Edition: A Clinical Orientation, Fourth Edition. McGraw-Hill Education, New York, NY

Sellars W (1997) Brandom R, Rorty R (eds) Empiricism and the Philosophy of Mind. Harvard University Press, Cambridge, MA

Snowdon PF (2005) The formulation of disjunctivism: A response to fish. Proceedings of the Aristotelian Society 105(1):129-141

Soteriou M (2014) The disjunctive theory of perception. The Stanford Encyclopedia of Philosophy http://plato.stanford.edu/archives/sum2014/entries/perception- 
disjunctive/

Tye M (2007) Intentionalism and the argument from no common content. Noûs 41(1):589-613 